\title{
Nitric Oxide and $\beta$-Adrenergic Mechanisms Modify Contractile Responses to Norepinephrine in Ovine Fetal and Newborn Cerebral Arteries ${ }^{1}$
}

\author{
I. CRAIG WAGERII:, WARREN MOLIKEN, AND PIERANTONIO RUSSO
}

Departments of Surgery and Physiology Temple University School of Medicine and St. Christopher's Hospital for Children Philadelphia, Pennsylvania 19102

\begin{abstract}
Ovine fetal cerebral arteries exhibit an enhanced contractile response to norepinephrine (NE) compared with newborns and adults. It is possible that $\beta$-adrenergic receptors and/or nitric oxide (NO), a putative endothelium-dependent relaxing factor, differentially modulate cerebrovascular responsiveness to NE as a function of development. The present study cvaluated the effect of the $\beta$-adrenoceptor antagonist, propranolol, and the NO synthase inhibitor, $N^{\mathrm{G}}$-nitro-l-arginine methyl ester (INAME), on the contractile response of isolated middle cercbral artery (MCA) and basilar artery (BA) to Ni: during fetal development. MCAs isolated from four preterm fetal lambs ( $105 \mathrm{~d}$ of gestation), seven near-term fetal lambs (125-130 d of gestation), and eight newborn lambs (2-7 d of age) were evaluated using organ baths. BAs isolated from the near-term fetal and newborn lambs were also evaluated. Contractile reactivity of MCAs to NE decreased significantly during fetal maturation as manifested by a marked decrease in $F_{\max }$ (maximal relative contractile force generated) and an increase in $\mathrm{EC}_{50}\left(F_{\max }-100 \pm 7,41 \pm 7\right.$, and $28 \pm 8 \%$ of $\mathrm{KCl}$ contraction; $\mathrm{EC}_{50}-0.14 \pm 0.03,1.09 \div 0.36$, and $1.07 \pm$ $0.22 \mu \mathrm{M}$ for preterm fetus, near-term fetus, and newborn lamb MCAs, respectively, $p \leq 0.05)$. Propranolol treatment $\left(10^{-5} \mathrm{M}\right)$ increased $F_{\max }$ (2-fold) only for newborn lamb MCAs. Pretreatment with LNAME $\left(10^{4} \mathrm{M}\right)$ markedly enhanced the contractile
\end{abstract}

ABSTRACT

The activation of the sympatho-adrenal axis is considered to be unimportant to the regulation of cerebral blood flow in adults $(1,2)$; however, such is not necessarily the case for the fetus and neonate. Activation of sympathetic nerves constricted ccrcbral arterioles and decreased cerebral blood flow in newborn and fetal animal models (3-6). In addition, fetal cerebral arteries, both in vivo and in vitro, exhibited cnhanced reactivity to the sympathetic neurotransmitter, norepinephrine (NE) (79 ). These reports suggest that the neuroeffector system may be an important factor with respect to the developing cerebral

Correspondence: L. Craig Wagerle, Ph.D., Department of Cardiothoracic Surgery, Mail Stop 402, Hahnemann Lniversity, Broad and Vine Streets, Philadelphia, PA 19103.

' Presented in preliminary form in May 1994 at the annual meeting of the Society for Pediatric Research in Seattle, WA response to $\mathrm{NE}$ (7-fold decrease in $\mathrm{EC}_{50}$ and 2-fold increase in $F_{\text {rax }}, p<0.05$ ) for ncar-term fetus MCAs, whereas preterm fetus and newborn lamb MCAs were unaffected by the inhibitor. BAs were unresponsive to NE except for near-term fetus BAs in the presence of LNAME. The effect of NO-synthase inhibition on NE contractility was depencent on developmental age, being prominent near term. The data suggest that, in the more mature fetus, NO, presumably derived from endothelium, behaves as a functional antagonist to sympathetic vasoconstriction of the cerebrovasculature, and its apparent absence permits unrepressed sympathetic vasoconstriction in the premature brain. (Pediatr Res 38: 237-242, 1995)
NE, norepinephrine
Abbreviations
NO, nitric oxide
MCA, middle cerebral artery
BA, basilar artery
LNAME, $N^{\mathrm{G}}$-nitro-L-arginine methyl ester
$\mathbf{E C}_{50}$, effective drug concentration inducing $50 \%$ of maximal response
$F_{\text {max }}$, maximal force generated in response to drug

circulation and indicate that the maturation process is associated with a progressive loss of sympathetic reactivity.

As yet, the underlying mechanism(s) by which $\alpha$-adrenergic contraction is modulated during fetal and postnatal life is not known. Endothelium-dependent relaxing factor(s) are reported to interfere with NE-induced contractions (10-14), and ontogenic changes in endothelial nitric oxide (NO) production have been demonstrated in the pulmonary circulation of fetal sheep (15). The absence of endothelium-dependent relaxation in the immature cerebral circulation might effect an enhanced response to contractile stimuli. However, the fact that a functional cholinergic vasodilator capability was expressed in fetal lambs by $90 \mathrm{~d}$ of gestation indicates that cerebrovascular endothelium-dependent vasodilator mechanisms are present early in fetal life (16). In addition to NO, alterations in 
$\beta$-adrenoceptor density and/or function in various vascular beds can change significantly during aging (17-20) and possibly modulate cerebrovascular reactivity to NE (21).

The purpose of this investigation was to evaluate the potential role of $\beta$-adrenergic receptor activity and/or NO synthase in the age-dependent alteration of the cerebrovascular contractile response to NE in the fetal and newborn lamb. The middle cerebral artery (MCA) and basilar artery (BA) have been the most widely studied cerebral arteries, in vitro, in adults and fetuses. Therefore, the contractile response to NE of MCA and $\mathrm{BA}$ isolated from fetal ( 0.70 to 0.83 gestation) and newborn lambs were evaluated and compared using tissue bath technique. For each artery studied, parallel experiments were performed in the presence of the $\beta_{1}, \beta_{2}$-adrenoceptor antagonist, propranolol, or the NO synthase inhibitor, $N^{\mathrm{G}}$-nitro-L-arginine methyl ester (LNAME) in addition to propranolol.

\section{METHODS}

Newborn lambs were killed with pentobarbital sodium (115 $\mathrm{mg} / \mathrm{kg}$, i.v.). Pregnant ewes and fetuses were similarly killed, and the fetuses were removed. The skull was opened and the brain was rapidly removed and placed into a dissecting dish containing physiologic saline. Under a dissecting microscope $(10 \times)$, MCAs and BAs were dissected free from the pial surface and immediately placed in Kreb's buffer with the following composition (mM): $\mathrm{NaCl}(128), \mathrm{KCl}$ (5), $\mathrm{CaCl}_{2}$ (2.5), $\mathrm{MgCl}_{2}$ (1.2), $\mathrm{NaHCO}_{3}(22), \mathrm{NaH}_{2} \mathrm{PO}_{4}$ (1.2), and glucose (11.5). The removed arteries were cut into 3-4-mm long ring segments, and each segment was gently mounted on stainless steel triangles (0.005-inch diameter) and suspended horizontally between a Grass force transducer (FT.03C) and a micrometer-controlled post. The glass tissue chamber $(10 \mathrm{~mL})$ was filled with the buffer, bubbled with $95 \% \mathrm{O}_{2}+5 \% \mathrm{CO}_{2}$, and warmed to $37^{\circ} \mathrm{C}$ by a circulating water bath. The suspended vessels were stretched to a resting tension of 0.75 $\mathrm{g} / 3-\mathrm{mm}$ ring length (the optimal tension for maximum active contraction based on length-tension studies; data not shown) and maintained at a steady state resting tension in the bath for at least $60 \mathrm{~min}$ before beginning the experiments. Then the rings were induced to contract by replacing the Kreb's solution with potassium-Kreb's solution $(10 \mathrm{~mL})$ containing $120 \mathrm{mM}$ $\mathrm{KCl}$ and $13 \mathrm{mM} \mathrm{NaCl}$ ( $\mathrm{KCl}$ stimulus). Once the peak contraction was obtained, the bath was washed with the normal Kreb's buffer, and the rings were allowed to return to their normal resting tension. This was repeated until the magnitude of successive $\mathrm{KCl}$ contractions was closely matched. The peak response to the $\mathrm{KCl}$ stimulus was used as a reference point for standardizing the subsequent experimental responses to contractile stimuli $(9,17)$. In select arteries the functional integrity of endothelium was confirmed by the presence of a relaxation to the addition of calcium ionophore, A23187 $\left(10^{-6} \mathrm{M}\right)$, to rings precontracted with NE (22-24).

Experiments were performed on a total of $52 \mathrm{MCA}$ and 35 BA segments isolated from four preterm fetal lambs (105 d of gestation), seven near-term fetal lambs (125-130 d of gestation), and eight newborn lambs (2-7 d of age). Four to eight $\mathrm{MCA}$ ring segments and two to four $\mathrm{BA}$ ring segments were obtained from each animal and were placed in tissue bath as described. Cumulative dose response curves to NE $\left(10^{-8}-10^{-5}\right.$ $\mathrm{M})$ were performed in the presence of propranolol $\left(10^{-5} \mathrm{M}\right)$ or propranolol + LNAME $\left(10^{-4} \mathrm{M}\right)$. Control (untreated) segments were run in parallel with the treated samples. Propranolol and LNAME were added to the bath at 20 and $10 \mathrm{~min}$ before beginning the NE dose-response determination, respectively. In some cases, the addition of LNAME caused a modest contraction (see Results). In those cases, the new steady state tension was taken as baseline for the purpose of the evaluating the subsequent NE response.

All compounds were prepared immediately before use in the tissue bath. Norepinephrine- $\mathrm{HCl}$, propranolol- $\mathrm{HCl}, \mathrm{N}^{\mathrm{G}}$-nitroL-arginine methyl ester- $\mathrm{HCl}$, and $\mathrm{A} 23187$ were purchased from Research Biochemicals Inc., Natick, MA.

Statistical Analysis. Values are presented as means \pm SEM. The contractile force generated by each ring segment obtained from preterm fetus, near-term fetus, and newborn lamb cerebral arteries was normalized to the maximal force generated by that same segment to $120 \mathrm{mM} \mathrm{KCl}$. Each dose-response curve was fit to the Hill equation and the $\mathrm{EC}_{50}$ (effective NE concentration inducing $50 \%$ of maximal contraction) was determined. Differences in the $\mathrm{EC}_{50}$ were identified by analysis of variance with repeated measures when appropriate. The arterial responses to NE and the effect of inhibitors were analyzed with a two-way analysis of variance with repeated measures; factor A was developmental age, factor B was inhibitor treatment. Student-Newman-Kuels test was used when appropriate. Differences were considered significant when $p \leq 0.05$.

\section{RESULTS}

The maximal contractile force generated in response to $\mathrm{KCl}$ challenge increased significantly with gestational age from $1.07 \pm 0.08 \mathrm{~g}$ to $2.56 \pm 0.27 \mathrm{~g}$ and $3.29 \pm 0.23 \mathrm{~g}$ for preterm fetus MCA, near-term fetus MCA, and newborn lamb MCA, respectively $(p<0.05)$, which is consistent with the increase in vessel wall thickness that occurs during development (9). The maximal contractile forces generated in response to $\mathrm{KCl}$ challenge by near-term fetus BA and newborn lamb BA were not different, $2.45 \pm 0.25$ and $2.42 \pm 0.19 \mathrm{~g}$, respectively. Preterm fetus BA was not studied.

The maximal force $\left(F_{\max }\right)$ generated in response to NE, when expressed in absolute grams of force per ring, did not change with development $(1.10 \pm 0.17,1.02 \pm 0.12$, and 1.05 $\pm 0.38 \mathrm{~g}$ for preterm fetus, near-term fetus, and newborn lamb MCA, respectively). However, when normalized to the respective $\mathrm{KCl}$ response, the $F_{\max }$ in response to $\mathrm{NE}$ was significantly decreased as a function of gestational age (Fig. 1, Table 1); to one-half for near-term fetus and to one-third for newborn lamb MCA, compared with that of preterm fetus MCA. There was also a significant decrease in sensitivity to NE during fetal development as manifested by an increase in the $\mathrm{EC}_{50}$ from $0.14 \pm 0.03,1.09 \pm 0.36$, and $1.07 \pm 0.22 \mu \mathrm{M}$ for preterm fetus, near-term fetus, and newborn lamb MCA, respectively (Table 1). BA from newborn lamb and near-term fetuses did not respond to $\mathrm{NE}$. 


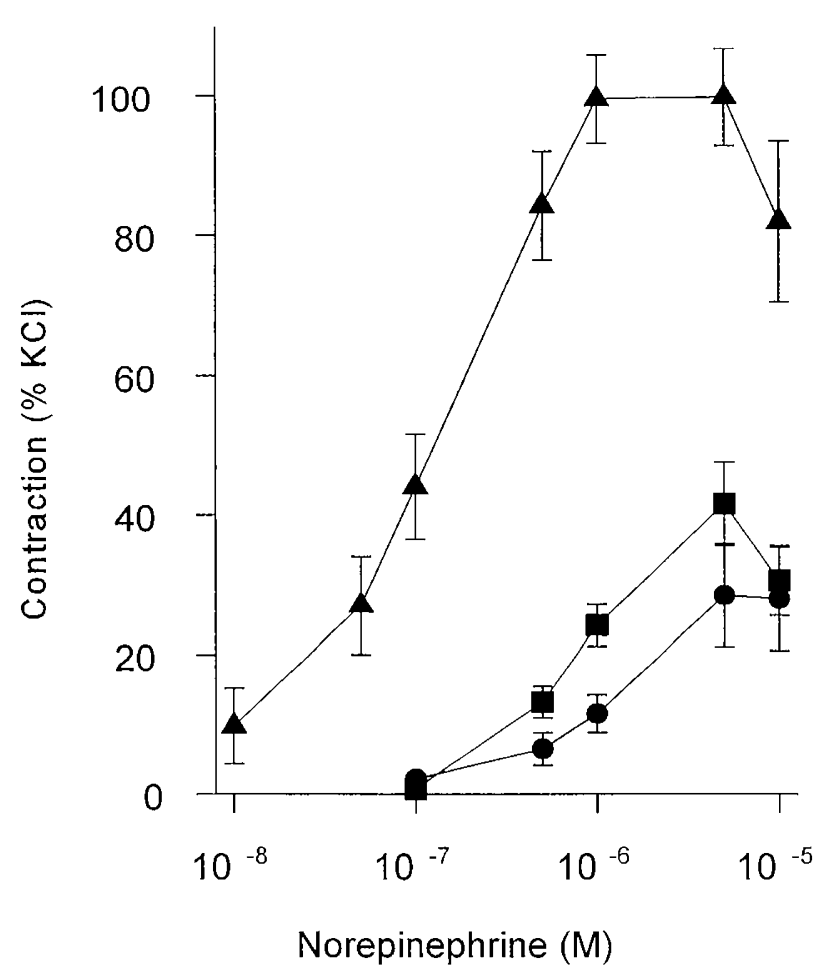

Figure 1. Dose-response curve for norepinephrine-induced contraction of middle cerebral artery rings isolated from newborn lambs $(\boldsymbol{\theta})$, near-term fetal lambs $(\boldsymbol{\square})$ and preterm fetal lambs $(\boldsymbol{\Delta})$. Force of contraction is expressed as percent of the maximal force attained for the same preparations in response to $120 \mathrm{mM} \mathrm{KCl}$ challenge. $F_{\max }, \mathrm{EC}_{50}$, and number of arteries are given in Table 1. There was a statistically significant interaction between gestational age and norepinephrine concentration $(p<0.05)$ by two-way analysis of variance. Values are mean \pm SEM.

Administration of propranolol $\left(10^{-5} \mathrm{M}\right)$ to the tissue bath had no effect on the baseline tension of MCAs or BAs for any of the age groups. The subsequent addition of LNAME $\left(10^{-4}\right.$ M) to the tissue bath, however, caused contraction in all three age groups $(14 \pm 5,14 \pm 5$, and $2 \pm 1 \%$ of $\mathrm{KCl}$ response for preterm fetus, near-term fetus, and newborn lamb, respectively). The magnitude of the contraction induced by LNAME was significantly diminished in the newborn lamb MCA when compared with both preterm and near-term fetus MCA $(p<0.001)$.
The effects of propranolol and propranolol + LNAME on the contractile response to NE for the three developmental age groups are presented in Table 1 and in Figures 2 and 3 for MCA and BA, respectively. Propranolol significantly augmented the NE-induced contraction in newborn lamb MCA, manifested by an increase in $F_{\text {max }}$. Propranolol did not significantly affect the NE response in either near-term or preterm fetus MCA. Propranolol + LNAME significantly augmented the NE-induced contraction in near-term fetus MCA as manifested by a 2-fold increase in the $F_{\max }$ and a 7 -fold decrease in the $\mathrm{EC}_{50}$. Propranolol + LNAME also significantly augmented the NE response in newborn lamb MCA, however, it was not different from that of propranolol alone. Propranolol + LNAME did not affect the NE-induced contraction in the preterm fetus MCA. After propranolol + LNAME treatment, the response to NE for near-term fetal lamb MCA was no longer significantly different from that of preterm fetal lamb MCA.

Propranolol treatment did not unmask a contractile response to NE in either newborn lamb or near-term fetus BA (Fig. 3 and Table 1). Subsequent LNAME treatment, however, did expose a small contractile response to $\mathrm{NE}$ in three of five newborn lamb BA. LNAME treatment also significantly augmented the previously absent response to NE for near-term fetal lamb BA. Preterm fetal BA was not studied.

\section{DISCUSSION}

The findings of the present study offer evidence for at least two vascular regulatory elements, i.e. NO synthase activity and $\beta$-adrenoceptor activity, which may play a role in the functional attenuation of NE reactivity of the cerebral circulation during perinatal development in sheep. Both regulatory elements appear to be activated by NE and both act to modify the NE-induced contraction of cerebral arteries. The NE-induced NO synthase activity appears to be the dominant endogenous inhibitor pathway operating late in fetal life and perhaps is more efficacious because of its influence even at low concentrations of NE. $\beta$-Adrenoceptor activation may also play a significant role in attenuating the NE-induced contraction during postnatal life but may be limited to the high concentration range of NE. The data suggest that NO formation by vascular

Table 1. $E C_{50}(\mu M)$ and $F_{\max }(\%$ of $\mathrm{KCl}$ contraction) for norepinephrine-induced contraction of cerebral arteries from fetal and newborn sheep

\begin{tabular}{|c|c|c|c|c|c|c|}
\hline \multirow[b]{2}{*}{ Arteries } & \multicolumn{2}{|c|}{ Preterm fetus } & \multicolumn{2}{|c|}{ Near-term fetus } & \multicolumn{2}{|c|}{ Newborn } \\
\hline & $\mathrm{EC}_{50}$ & $F_{\max }$ & $\mathrm{EC}_{50}$ & $F_{\max }$ & $\mathrm{EC}_{50}$ & $F_{\max }$ \\
\hline \multicolumn{7}{|l|}{$\mathrm{MCA}$} \\
\hline Control & $0.143 \pm 0.028(8)$ & $100 \pm 7$ & $1.09 \pm 0.36(5)^{*}$ & $41 \pm 7^{*}$ & $1.07 \pm 0.22(5)^{*}$ & $28 \pm 8^{*}$ \\
\hline Propranolol & $0.141 \pm 0.061(5)$ & $100 \pm 20$ & $0.76 \pm 0.14(6)$ & $50 \pm 11$ & $0.69 \pm 11$ & $52 \pm 7 \dagger$ \\
\hline Propranolol + LNAME & $0.080 \pm 0.025(5)$ & $96 \pm 9$ & $0.16 \pm 0.04(5) \dagger$ & $85 \pm 8 \dagger$ & $0.74 \pm 0.28(5)^{*}$ & $58 \pm 12 *+$ \\
\hline \multicolumn{7}{|c|}{ 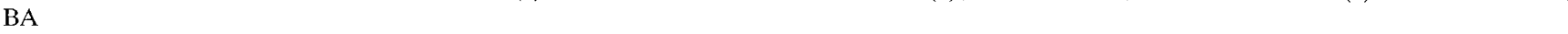 } \\
\hline Control & & & NR & NR & NR & NR \\
\hline Propranolol & & & NR & NR & NR & NR \\
\hline Propranolol + LNAME & & & $0.10 \pm 0.93(3) \dagger$ & $30 \pm 9 \dagger$ & $0.40 \pm 0.30(3)$ & $7 \pm 4(5)$ \\
\hline
\end{tabular}

Propranolol concentration was $10 \mu \mathrm{M}$. LNAME, $100 \mu \mathrm{M}$. NR signifies no response to norepinephrine. Number of arteries are in Parentheses. Preterm fetus basilar arteries were not studied.

* Significantly different from preterm fetus.

$\dagger$ Significantly different from control; $p \leq 0.05$. 


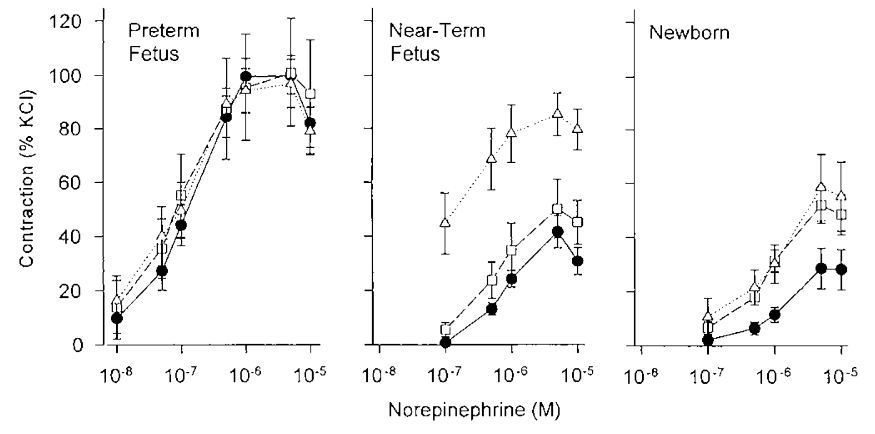

Figure 2. Effect of $\beta$-adrenergic antagonist, propranolol $(10 \mu \mathrm{M})$ and LNAME $(100 \mu \mathrm{M})$ on the norepinephrine-induced contraction of middle cerebral artery rings ( $\bullet$ control; $\square$, propranolol; $\triangle$, propranolol + LNAME) isolated from preterm fetal lambs (left panel), near-term fetal lambs (middle panel), and newborn lambs (right panel). $F_{\max }, \mathrm{EC}_{511}$, and number of arteries are given in Table 1. Values are mean \pm SEM.

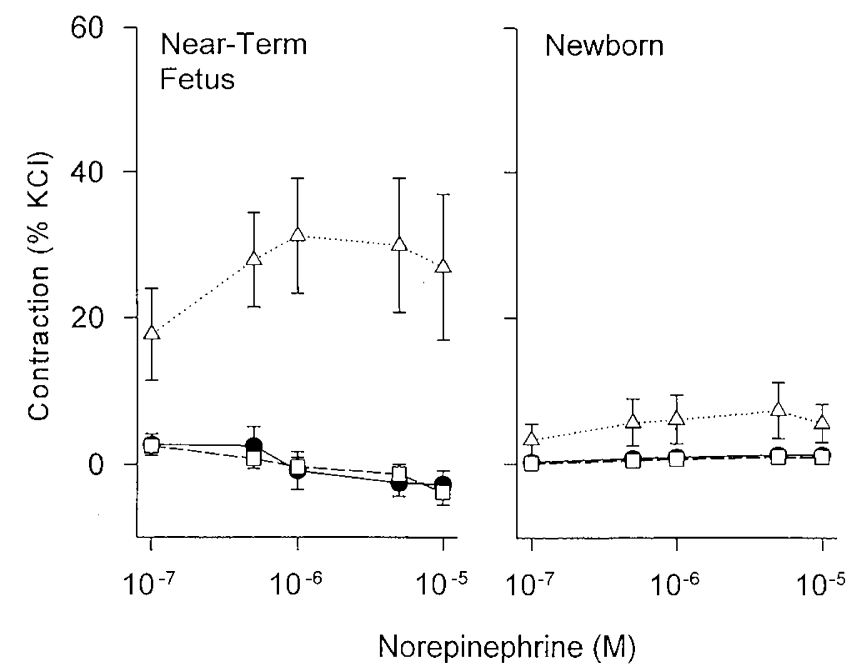

Figure 3. Effcct of $\beta$-adrenergic antagonist, propranolol $(10 \mu \mathrm{M})$ and LNAME $(100 \mu \mathrm{M})$ on the norepinephrine-induced contraction of basilar artery rings ( $\bullet$, control; $\square$, propranolol; $\triangle$, propranolol + LNAME) isolated from near-term fetal lambs (left panel) and newborn lambs (right panel). $F_{\max }, \mathrm{EC}_{50}$, and number of arteries are given in Table 1 . Values are mean \pm SEM.

endothelial cells plays an important role in the modulation of cerebrovascular $\alpha$-adrenergic contraction during fetal development.

These conclusions are based on the finding that the respective pattern and efficacy of NO synthase inhibition and $\beta$-adrenoceptor blockade on the characteristic NE-induced contraction of MCA was distinctive for each developmental age group studied. Neither NO synthase inhibition nor $\beta$-adrenergic blockade further enhanced the already substantial response of preterm fetus MCA to NE. In contrast, the response of the near-term fetus MCA to NE was significantly diminished from that of preterm fetus and NO synthase inhibition markedly increased both the relative force of contraction and sensitivity to the neurotransmitter. Indeed, the response of near-term fetus MCA to NE in the presence of LNAME was not significantly different from that of the untreated preterm fetus MCA. Finally, the NE response of newborn lamb MCA was augmented significantly by propranolol whereas the addition of LNAME had little further effect.
In both fetal and newborn lambs, the characteristic response of the BA to NE differed from that of the MCA as was previously reported (9). In the present study, the BA was unresponsive to $\mathrm{NE}$; however, a significant contractile response could be elicited for the BA, predominately in the near-term fetus, in the presence of LNAME. Thus, in near-term fetus BA as well, vascular production of NO, presumably via endothelium, dramatically attenuates $\alpha$-adrenergic contraction.

The LNAME-sensitive component of the NE responsiveness observed for the near-term fetus MCA is most probably that of constitutive NO synthase activity expressed in vascular endothelium (25), although NO generated by vascular smooth muscle cells may also occur $(26,27)$. For that matter, administration of LNAME, in and of itself, contracted MCAs of both preterm and near-term fetuses suggesting that there was constitutive NO synthase activity even in the absence of NE in the MCAs of both fetal ages. However, LNAME augmented the NE response only in the MCAs from the near-term fetuses. Thus, the presence or absence of spontaneously released NO was probably not singularly responsible for the diminished NE-induced contraction observed with maturation. It is likely, therefore, that for the near-term fetus MCA, NE stimulated an increase in NO formation via vascular $\alpha$-adrenoceptors presumably located on the endothelium (10).

Endothelium removal has been shown to enhance the maximum force of contraction and sensitivity of aorta and mesenteric arteries of adult rats to both $\alpha_{1}$ and $\alpha_{2}$-adrenergic agonists $(12,13)$. In other cases, endothelium-dependent modulation of NE-induced contraction appears to involve primarily $\alpha_{2}$-adrenoceptors located on endothelial cells. In fact, $\alpha_{2}$-adrenergic agonists have been shown to cause endotheliumdependent relaxation in select vascular preparations $(10,11$, 14). Thus, in the near-term fetus and newborn lamb MCA as well, NE probably stimulated endothelium formation of NO via either $\alpha_{1}$ - and/or $\alpha_{2}$-adrenoceptors. Furthermore, the implication of this study that endothelium-dependent modulation of cerebrovascular adrenergic reactivity is dependent on developmental age may be consistent with reports of differential expression of vascular $\alpha_{1}$ - and $\alpha_{2}$-adrenoceptors during development $(1,28,29)$.

Pearce et al. (9), have reported developmental changes in both morphology and reactivity of cerebral arteries from term fetal lambs (139-141 d of gestation) and newborn lambs (3-7 d old). Specifically, the transition from fetal life was associated with a decrease in vessel water content, an increase in vessel wall stiffness and thickness, an increase in the maximum active stress development, and a decrease in the maximum contractile response to amines (serotonin and NE). Our findings support the latter observation and extend it to earlier stages of fetal development. The relative force of contraction induced by NE in preterm fetus MCAs was significantly enhanced compared with that of near-term fetus MCAs and newborn lamb MCAs and there was a significant decrease in sensitivity (i.e. increase in $\mathrm{EC}_{50}$ ) as a function of developmental age, exposing the relative increased efficiency for NE-induced force generation in the immature cerebral circulation.

From a functional standpoint, the more efficient contractility of premature cerebral arteries to the neurotransmitter would 
likely precipitate a more potent sympathetic vasoconstriction, in vivo. Thus, reflex activation of sympathetic nerves and/or humoral activation of vascular adrenoceptors may significantly decrease cerebral perfusion. Using the closed cranial window preparation, we have previously shown that NE-induced vasoconstriction of cerebral arteries, in vivo, was enhanced in preterm fetuses of $<120 \mathrm{~d}$ of gestation compared with newborn lambs (8). Furthermore, fetal lambs as early as $111 \mathrm{~d}$ of gestation, approximately the same age as the preterm fetuses of the present study, exhibited a functional sympathetic innervation of cerebral arterioles, which, when stimulated, induced vasoconstriction (8). In newborn pigs, sympathetic nerves significantly reduce cerebral blood flow during pathophysiologic events known to be associated with sympatho-adrenal activation, i.e. bicuculline-induced seizures (30) and acute asphyxia $(31,32)$. Whether sympathetic vasoconstriction significantly attenuates cerebral blood flow in the fetus has yet to be determined; however, it was postulated that immature neuroeffector mechanism(s) may be a factor in the diminished cerebral blood flow response to hypoxemia reported in premature fetal sheep (33).

With regard to the possible effects of blood-borne NE on fetal cerebral arteries, elevation of plasma NE was reported to have no effect on cerebral blood flow in fetal sheep of 125-135 $\mathrm{d}$ of gestation, suggesting that the blood-brain barrier to catecholamines has developed (34). On the other hand, a functional endothelium so exposed to circulating NE may produce $\mathrm{NO}$ and thus mask any vasoconstriction in that model. In less mature fetuses, however, the enhanced reactivity to NE may become important, especially in the presence of even minor damage to the blood-brain barrier. It seems readily apparent that a well developed endothelium may be critical to the prevention of unmitigated vasoconstriction in response to sympatho-adrenal activation in the fetal cerebral circulation.

In adult animal models, the neuroeffector system in cerebral arteries generally exhibits unique features, distinct from those commonly observed for peripheral arteries (1). These features include a reduced capacity to elicit maximal contraction, limited receptor reserve, reduced NE sensitivity, possible expression of unique $\alpha$-adrenoceptor subtypes, relatively small vasoconstrictor responses to sympathetic stimulation, and when sympathetic vasoconstriction is present, it is limited to large arteries. The present study along with previous reports $(4,6$, 30,31 , however, demonstrate a remarkable capacity for sympathetic regulation of cerebral blood flow during the perinatal period that is specifically diminished as the animals mature (7-9, 28). Indeed, preterm fetal lamb MCA exhibited a NE sensitivity $\left(\mathrm{EC}_{50}=1.4 \times 10^{-7} \mathrm{M}\right)$ and a capacity to elicit a maximal contraction $(100 \%$ of $\mathrm{KCl}$ contraction) that were virtually identical to that normally attributed to noncerebral arteries (1). It would appear that the development of a functional neuroeffector system in the cerebral circulation precedes that of certain important endogenous inhibitory systems, such as a NE sensitive NO-generating system and/or functional vascular $\beta$-adrenoceptors. Therefore, we may surmise that the atypical behavior of the neuroeffector system of adult cerebral arteries reflects the ontogeny of functional suppression of sympathetic reactivity.
In adult sheep MCA, endothelium removal had no effect on the contractile response either to NE or to serotonin (35). In the present study, neither propranolol nor LNAME completely restored the reactivity of newborn lamb MCA to $\mathrm{NE}$ to that observed for preterm fetuses. These findings suggest that additional, as yet, unidentified factors may come into play to modulate NE reactivity as the cerebral circulation matures. Certainly, other endogenously produced factors, i.e. eicosanoids, could similarly modulate sympathetic vasoconstriction in neonates (36). Also, postnatal changes in vascular and/or endothelial cell adrenoceptor expression and density occur with development $(17,28)$. This may explain, in part, reports that cerebral arteries of adult pigs exhibited only $\beta$-adrenergic vasodilation in response to NE whereas neonatal pigs exhibited vasoconstriction via vascular $\alpha_{1}$ - and $\alpha_{2}$-adrenoceptors $(3,21,37)$. Finally, an alternative process perhaps modulating NE reactivity could entail changes in postreceptor signaling mechanisms during development (38).

In conclusion, these findings implicate a NO synthasedependent pathway in fetal lamb cerebral arteries that exerts functional inhibition of the contraction induced by sympathetic activation and is expressed during the last third of gestation. Subsequent maturation of vascular $\beta$-adrenergic receptors may supplant this role in the newborn cerebral circulation. The data suggest that, in the more mature fetus, NO behaves as a functional antagonist to sympathetic vasoconstriction of the cerebrovasculature, and its apparent absence permits unrepressed sympathetic vasoconstriction in the premature brain.

\section{REFERENCES}

1. Bevan JA, Duckworth J, Laher I, Oriowo MA, McPherson GA, Bevan RD 1987 Sympathetic control of cerebral arteries: Specialization in receptor type, reserve, affinity, and distribution. FASEB J 1:193-198

2. Heistad DD, Marcus ML 1978 Evidence that neural mechanisms do not have important effects on cerebral blood flow. Circ Res 42:295-302

3. Wagerle LC, Delivoria-Papadopoulos M $1987 \alpha$-Adrenergic receptor subtypes in the cerebral circulation of newborn piglets. Am J Physiol 252:R1092-R1098

4. Wagerle LC, Kumar SP, Delivoria-Papadopoulos M 1986 Effect of sympathetic nerve stimulation on cerebral blood flow in newborn piglets. Pediatr Res 20:131-135

5. Wagerle LC, Heffernan TM, Sacks LM, Delivoria-Papadopoulos M 1983 Sympathetic effect on cerebral blood flow regulation in hypoxic newborn lambs. Am J Physiol 245:H487-H494

6. Busija DW, Leffer CW, Wagerle LC 1985 Responses of newborn pig pial arteries to sympathetic nervous stimulation and exogenous norepinephrine. Pediatr Res 19:1210-1214

7. Hayashi S, Park MK, Kuehl TJ 1984 Higher sensitivity of cerebral arteries isolated from premature and newborn baboons to adrenergic and cholinergic stimulation. Life Sci 35:253-260

8. Wagerle LC, Kurth CD, Roth RA 1990 Sympathetic reactivity of cerebral arteries in the developing fetal lamb and adult sheep. Am J Physiol 258:H1432-H1438

9. Pearce WJ, Hull AD, Long DM, Longo LD 1991 Developmental changes in ovine cerebral artery composition and reactivity. Am J Physiol 261:R458-R465

10. Vanhoutte PM, Miller VM $1989 \alpha_{2}$-Adrenoceptors and endothelium-derived relaxing factor. Am J Med 87(suppl 3C):1S-5S

11. Angus JA, Cocks TM, Satoh K 1986 The $\alpha$-adrenoceptors on endothelial cells. Fed Proc 45:2355-2359

12. Carrier GO, White RE 1985 Enhancement of $\alpha-1$ and $\alpha-2$ adrenergic agonist-induced vasoconstriction by removal of endothelium in rat aorta. J Pharmacol Exp Ther 232:682-687

13. White RE, Carrier GO $1987 \alpha_{1}$ - and $\alpha_{2}$-adrenoceptors agonist-induced contraction in rat mesenteric artery upon removal of endothelium. Eur J Pharmacol 122:349-352

14. Miller VM, Vanhoutte PM 1985 Endotheial $\alpha_{2}$-adrenoceptors in canine pulmonary and systemic blood vessels. Eur J Pharmacol 118:123-129

15. Shaul PW, Farrar MA, Magness RR 1993 Pulmonary endothelial nitric oxide production is developmentally regulated in the fetus and newborn. Am J Physiol 265:H1056-H1063

16. Wagerle LC, Kurth CD, Busija DW 1992 Cholinergic reactivity of cerebral arteries in the developing foetal and newborn lamb. J Dev Physiol 17:51-54

17. Duckles SP, Banner $J_{\pi}$ W 1984 Changes in vascular smooth muscle reactivity during development. Annu Rev Pharmacol Toxicol 24:65-83 
18. Vapaavouri EK, Shinebourne EA, Williams RL, Heymann MA, Rudolph AM 1973 Development of cardiovascular responses to autonomic blockade in intact fetal and nconatal lambs. Biol Nconate 22:177-188

19. Kobayashi S, Tsukahara K, Sugita K, Matsuo K, Nagata T 1981 Histochemical studies on the postnatal development of autonomic nerves in mice cerebral arteries. Histochemistry 73:15-20

20. Kobayashi H, Cazzaniga A, Spano P, Trabucchi M 1982 Ontogenesis of $\alpha$ - and $\beta$-receptors located on cerebral microvessels. Brain Res 242:358-360

21. Lee TJ, Kinkhead LR, Sarwinski S 1982 Norepinephrine and acetylcholine transmitter mechanisms in large cerebral arteries of the pig. J Cereb Blood Flow Metab $2: 439-450$

22. Hull AD, Long DM, Longo LD, Pearce WJ 1992 Pregnancy-induced changes in ovine cerebral arteries. Am J Physiol 262:R137-R143

23. Rosenblum WI, McDonald M, Wormley B 1989 Calcium ionophore and acetylcholine dilate arterioles on the mouse brain by different mechanisms. Stroke 20:13911395

24. Kanamaru K, Waga S, Kojima T, Fujimoto K, Hiroji I 1987 Endothelium-dependent relaxation of canine basilar arteries. Part 1: Difference between acetylcholine- and A23187-induced relaxation and involvement of lipoxygenase metabolite(s). Stroke 18:932-937

25. Ignarro LJ 1989 Biological actions and properties of endothelim-derived nitric oxide formed and released from artery and vein. Circ Res 65:1-21

26. Mollace V, Salvemini D, Anggard E, Vane J 1991 Nitric oxide from vascular smooth muscle cclls: Regulation of platelet reactivity and smooth muscle cell guanylate cyclase. Br J Pharmacol 104:633-638

27. Marczin N, Papapetropoulos A, Catravas JD 1993 Tyrosine kinase inhibitors suppress cndotoxin- and IL- $1 \beta$-induced NO synthesis in aortic smooth muscle cells. Am J Physiol 265:H1014-H1018
28. Tayo FM, Bevan RD, Bevan JA 1986 Changes in postjunctional $\alpha$-adrenoceptors during postnatal growth in rabbit arteries. Circ Res 58:867-873

29. Fedida D, Braun AP, Giles WR $1993 \alpha_{1}$-Adrenoceptors in myocardium: Functional aspects and transmembrane signaling mechanisms. Physiol Rev 73:469-487

30. Kurth CD, Wagerle LC, Delivoria-Papadopoulos M 1988 Sympathetic regulation of cerebral blood flow during seizures in newborn lambs. Am J Physiol 255:H563-H568

31. Goplerud JM, Wagerle LC, Delivoria-Papadopoulos M 1991 Sympathetic nerve modulation of regional cerebral blood flow during asphyxia in newborn piglets. Am J Physiol 260:H1575-H1580

32. Hernandez MJ, Hawkins RA, Brennan RW 1982 Sympathetic control of regional cerebral blood flow in the asphxiated newborn dog. In: Heistad DD, Marcus ML (eds) Cerebral Blood Flow. Effects of Nerves and Neurotansmitters. Elsevicr, New York, pp 359-366

33. Gleason CA, Hamm C, Jones Jr MD 1990 Cerebral responses to hypoxia in immature fetal sheep. Am J Physiol 258:1064-1069

34. Lorijn RHW, Longo LD 1980 Norcpinephrine elevation in the fetal lamb: Oxygen consumption and cardiac output. Am J Physiol 239:R115-R122

35. Gaw AJ, Wadsworth RM 1989 Pharmacological characterization of postjunctional $\alpha$-adrenoceptors in cerebral arteries from the shecp. Br J Pharmacol 98:741-746

36. Busija DW, Leffler CW 1987 Eicosanoid synthesis elicited by norepinephrine in piglet parietal cortex. Brain Res 4()3:243-248

37. Busija DW, Leffler CW 1987 Exogenous norepinephrine constricts cerebral artcrioles via $\alpha_{2}$-adrenoceptors in newborn pigs. J Cereb Blood Flow Mctab 7:184-188

38. Wagerle LC, Moliken W, Russo P 1994 Developing lamb cerebral arteries exhibit differential sensitivity in inhibitors of protein kinase $C$ and tyrosine kinase. FASEB J 8:A359(abstr) 